\title{
Improving cardiovascular health in Spanish seafarers
}

\author{
Maria del Carmen Romero-Paredes ${ }^{1,2}$, Luis Reinoso-Barbero ${ }^{3,4}$, \\ Maria Fernanda González-Gómez ${ }^{5}$, Fernando Bandrés-Moya ${ }^{2}$ \\ ${ }^{1}$ Instituto Social de la Marina, Maritime Health Service in Madrid, Spain \\ ${ }^{2}$ Toxicology and Medical Legislation Department, Faculty of Medicine, Complutense University of Madrid, Spain \\ ${ }^{3}$ Occupational Health, Occupational Health Service, Banco Popular Group, Madrid, Spain \\ ${ }^{4}$ Morphological Science and Biomedicine Department, Health Science Department, Health Science Faculty, \\ European University of Madrid, Spain \\ ${ }^{5}$ Occupational Health, Consejería de Sanidad, Regional Government of Madrid, Spain
}

\begin{abstract}
Background and aim: There is a high prevalence in the Spanish general population of some cardiovascular risk factors like overweight, obesity and hypercholesterolaemia. But there is lack of research on Spanish seafarers. On the other hand, there is strong evidence of the cardiovascular risk predictive value of some biomarkers. The purpose of this work was to study the convenience of the introduction of detailed diet questionnaires and the measurement of some biomarkers in the pre-embarkation medical examination. Materials and methods: Seafarers undergoing medical checkup during 2011 in Madrid, Spain $(n=334)$. Overweight and obese subjects received general advice on healthy diet and physical activity. Seventy-four of them were followed up in 2012 and 2013. Glycated haemoglobin (HbA1c), high-sensitivity C-reactive protein (hs-CRP), thyrotropin (TSH) and microalbuminuria were measured in two selected groups of patients in 2011. Results: Overweight and obesity were present in 207 (62\%) individuals of the studied population. Those followed up in 2012 and 2013 showed a reduction of body mass index, waist circumference and total cholesterol values. We observed risk value of HbA1c in 60 (35.5\%) individuals with significant association to other cardiovascular risk factors. Microalbuminuria appeared in subjects with high blood pressure. High TSH and hs-CRP were not significantly present in our population.

Conclusions: 1. Measurement of HbA1c during medical checkups improves early detection of cardiovascular risk in seafarers. 2. Individuals with overweight and obesity responded positively to medical advice and diminished their risk factors, thus it may be more effective to introduce detailed questionnaires on this issue.
\end{abstract}

(Int Marit Health 2016; 67, 1: 3-8)

Key words: overweight, obesity, glycated haemoglobin, seafarers

\section{INTRODUCTION}

Several works have been carried out in the last decades, showing the high prevalence of some cardiovascular risk factors among the Spanish general population: high blood pressure and hypercholesterolaemia (> 40\%); obesity and smoke habit (> 27\%); and diabetes mellitus (>13\%) [1].

However, there is a lack of research on Spanish seafarers (nearly 70,000 workers nowadays), which usually work under hard conditions that need a particular administrative and sanitary regulation.

The last report of the Spanish Occupational Safety and Hygiene National Institute (2013) emphasizes the higher risks of working on board compared with other labour areas, including fourfold myocardial infarction and stroke risk.

Working seamen often spend long periods of time embarked and do not frequently visit physicians ashore. It is also very difficult to follow up the compliance of treatment due to the particular labour conditions on board, long periods offshore and wide geographical dispersion of these workers.

Usually, their sole contact with a physician is the pre-embarkation medical examination, which constitutes the best chance to detect and prevent any health problem. Accord-

Dr Maria del Carmen Romero-Paredes, Policlínica del Instituto Social de la Marina, Calle Gaztambide, 85. 28003 Madrid, Spain, tel: +34910000160,

e-mail: ma-carmen.romero@seg-social.es 
ing to Tim Carter: "The main approach to risk reduction (of accidents on board) is by the application of fitness criteria to seafarers during medical examinations" [2].

Pre-embarkation medical checkup's objective is to determine if seafarers' physical and psychological conditions are adequate to their work on board, with no risk for their own health, other crewmembers' or passengers' safety, according to Spanish Law (Real Decreto 1696/2007).

Seamen are obliged to undergo pre-embarkation checkup every 2 years, in ages from 21 to 50 , and every year if younger than 21 or older than 50 .

On the other hand, it is well known that the course of the atherosclerosis disease is silent during long periods of time; so acute ischaemic events take place often in apparently healthy people [3], which must be evaluated carefully.

Several studies have shown the predictive value of various biomarkers in the development of cardiovascular disease. We decided to include in this work the measurement of following parameters in a selected group: glycated haemoglobin (HbA1c) [4-7], high-sensitivity C-reactive protein (hs-CRP) [8-10], thyrotropin (TSH) [11-14], microalbuminuria [15-17], especially for their good cost-efficiency and easy accessibility.

The aim of the study was: 1) To establish if the introduction of more detailed dietary questionnaire and medical advice during pre-embarkation examinations would obtain better results in diminishing overweight and obesity among seafarers. 2) To determine if the measurement of some cardiovascular risk biomarkers means an improvement in the early detection of cardiovascular risk in seafarers during pre-embarkation medical checkups.

\section{MATERIALS AND METHODS}

During 2011, 334 patients went under pre-embarkation medical exam in the Maritime Health Service of Madrid, Spain, including anamnesis, physical examination and the measurement of some parameters established by our protocols, like glucose blood levels, total cholesterol, high density lipoprotein (HDL)-cholesterol, low density lipoprotein (LDL)-cholesterol and triglycerides.

During the pre-embarkation medical examinations, we observed a high prevalence of overweight and obesity among our population. Thus, we gave them general advice on healthy diet and physical activity to help them to lose weight and we decided to follow up these individuals in the next medical checkup ( 1 or 2 years later depending on their age). The recommendations consisted of reducing fat and carbohydrates intake and practicing aerobic physical activity for 20-30 min every day.

On the other hand, two groups of individuals were selected to measure HbA1c, hs-CRP, TSH and microalbuminuria in them.

The inclusion criteria in the first group were:

- Seafarer undergoing pre-embarkation medical checkup.
- Age between 50 (mean age for Spanish general population's studies consulted on cardiovascular risk) and 66 years (upper limit of age in our population).

The inclusion criteria in the second group:

- Seafarer undergoing pre-embarkation medical checkup.

- Age between 18 and 49 years with high blood pressure or hyperglycaemia or dyslipidaemia or obesity; also if having relatives with premature cardiovascular disease or diabetes mellitus.

The exclusion criteria for both groups were:

- Having suffered a cardiovascular event in the last 5 years.

- Presence of infectious or inflammatory illness at the moment of medical checkup.

Glycated haemoglobin was measured using the HPLC-Calibration NGSP (DCCT) technique. Its values are expressed in percentage. Cutoff point considered as cardiovascular risk predictive was $\geq 5.7 \%$.

High-sensitivity C-reactive protein was determined by immunoturbidimetry. It is expressed in $\mathrm{mg} / \mathrm{dL}$. Its normal value is $0.500 \mathrm{mg} / \mathrm{dL}$.

Thyrotropin was measured using chemiluminescence system and expressed as $\mu \mathrm{UI} / \mathrm{mL}$. Normal values are from 0.550 to $4.780 \mu \mathrm{UI} / \mathrm{mL}$. It is used as predictive cardiovascular risk biomarker when its value is under $0.10 \mathrm{mUI} / \mathrm{L}$ and over $10 \mathrm{mUl} / \mathrm{L}$.

Microalbuminuria was also measured by immunoturbidimetry. It is expressed in $\mathrm{mg} / \mathrm{L}$. Normal value is $<30 \mathrm{mg} / \mathrm{L}$. Its value as predictive cardiovascular risk biomarker is between 30 and $300 \mathrm{mg}$ per day.

\section{STATISTICAL ANALYSES}

We studied the distribution of risk factors in our population and the possibility of statistical association amongst themselves. Quantitative variables were encoded and categorised following risk criteria. Chi-square test, Fisher's exact test (for relations between categorical variables) and odds ratio $(\mathrm{OR})$ were used.

Some variables were dichotomised and we looked up for association with others, analysing OR, obtained by logistic binary regression. To determine the association among quantitative variables, lineal regression and correlation tests were utilised.

To carry out this study, we used the SSPS Statistics 21 Program.

\section{RESULTS}

\section{MAIN PARAMETERS IN THE POPULATION EXAMINED IN 2011}

The population examined during $2011(n=334)$ was mainly male $(86.2 \%$ men, $13.8 \%$ women) and young ( $44.9 \%$ older than 45 years; age range $23-66$ years, mean 47.13 
years). The most prevalent cardiovascular risk factors in our population were: high blood pressure (40.1\%), hypercholesterolaemia (49.7\%), tobacco use (33.5\%), overweight (44.6\%) and obesity (17.4\%) (Table 1).

\section{FOLLOW-UP OF THE SUBGROUP}

We managed to re-examine (in 2012 or 2013) 74 of the 207 subjects who presented overweight and obesity in

Table 1. Main variables observed in the population examined in $2011(n=334)$

\begin{tabular}{llll}
\hline Variable & Classification & N & $\%$ \\
\hline Sex & Men & 288 & 86.2 \\
& Women & 46 & 13.8 \\
Age & $<45$ years & 184 & 55.1 \\
& $\geq 45$ years & 150 & 44.9 \\
Blood pressure & No risk & 200 & 59.9 \\
Blood cholesterol & Risk & 134 & 40.1 \\
& No risk & 168 & 50.3 \\
Tobacco use & Risk & 166 & 49.7 \\
Weight & Non smoker & 222 & 66.5 \\
& Smoker & 112 & 33.5 \\
& Normal & 127 & 38 \\
Waist circumference & Overweight & 149 & 44.6 \\
& Obesity & 58 & 17.4 \\
Metabolic syndrome & No risk & 244 & 73.1 \\
& Risk & 84 & 25.1 \\
& Absent & 285 & 85.3 \\
& Present & 48 & 14.4
\end{tabular}

2011. All of them had received general medical advice on proper dietary and physical activity habits.

In the new medical checkup, we observed that:

- 31 (41.9\%) patients reduced their body mass index (BMI) (28 men, 3 women);

- 46 (62.2\%) subjects reduced their abdominal waist circumference (43 men, 3 women).

- 37 (50\%), showed lower values of total cholesterol (37 men, 1 woman).

The reduction of waist circumference and blood cholesterol was significant in men, but not in women (Table 2).

\section{WITH REGARD TO PREDICTIVE BIOMARKERS}

Glycated haemoglobin was measured in 172 patients and was $\geq 5.7 \%$ in 61 of them (35.5\%). No significance distribution among sexes was found (Table 3).

When considering each subgroup of selected patients separately, we found a higher prevalence of $\mathrm{HbA} 1 \mathrm{c} \geq 5.7 \%$ in the group of subjects older than 50 , with no significant difference though (Table 4).

Risk values of $\mathrm{HbA} 1 \mathrm{c}$ were significantly more prevalent among patients with glucose blood levels $\geq 100 \mathrm{mg} / \mathrm{dL}$ $(p<0.01)$ and among subjects with metabolic syndrome $(p<0.01)$. Metabolic syndrome is defined as the presence of at least three of following criteria: 1) Waist circumference $\geq 102 \mathrm{~cm}$ in men and $88 \mathrm{~cm}$ in women; 2) Triglycerides $\geq 150 \mathrm{mg} / \mathrm{dL}$ (or under treatment). 3) HDL-cholesterol $<40 \mathrm{mg} / \mathrm{dL}$ in men and $<50 \mathrm{mg} / \mathrm{dL}$ in women (or under treatment); 4) Blood pressure $\geq 130 / 85 \mathrm{~mm} \mathrm{Hg}$ (or under treatment); 5) Glucose blood level $\geq 100 \mathrm{mg} / \mathrm{dL}$ (or under treatment).

In relation to $\mathrm{BMI}, \mathrm{HbA} 1 \mathrm{c}$ was more prevalent among overweight and obese patients (World Health Organisation

Table 2. Evolution of followed-up population $(n=74)$

\begin{tabular}{|c|c|c|c|c|c|c|c|}
\hline \multirow[t]{2}{*}{ Parameter } & \multirow[t]{2}{*}{$\begin{array}{l}\text { Mean baseline values } \\
\text { (in 2011) }\end{array}$} & \multirow[t]{2}{*}{$\begin{array}{l}\text { Mean values after } \\
\text { medical advice } \\
\text { (in 2012-2013) }\end{array}$} & \multirow[t]{2}{*}{$\mathbf{P}$} & \multicolumn{2}{|c|}{$\begin{array}{l}\text { Improvement } \\
\text { (= reduction) } \\
\text { in 2012-2013 }\end{array}$} & \multicolumn{2}{|c|}{$\begin{array}{l}\text { No improvement } \\
\text { (= no reduction) } \\
\text { in } 2012-2013\end{array}$} \\
\hline & & & & $\mathbf{N}$ & $\%$ & $\mathbf{N}$ & $\%$ \\
\hline \multirow[t]{2}{*}{ Body mass index } & Men: 30.9 & 29.26 & $>0.05$ & 28 & 40.6 & 41 & 59.4 \\
\hline & Women: 30.7 & 30.8 & $>0.05$ & 3 & 60 & 2 & 40 \\
\hline Total & 29.2 & 29.37 & $>0.05$ & 31 & 41.9 & 43 & 58.1 \\
\hline \multirow{2}{*}{$\begin{array}{l}\text { Waist circumfe- } \\
\text { rence }[\mathrm{cm}]^{*}\end{array}$} & Men: 102.57 & 100.37 & $<0.05$ & 43 & 62,3 & 26 & 37.68 \\
\hline & Women: 90.8 & 88.8 & $>0.05$ & 3 & 60 & 2 & 40 \\
\hline Total & 101.8 & 99.6 & $<0.05$ & 46 & 62,2 & 28 & 37.8 \\
\hline \multirow{2}{*}{$\begin{array}{l}\text { Blood cholesterol } \\
{[\mathrm{md} / \mathrm{dL}]}\end{array}$} & Men: 219.8 & 211.7 & $<0.05$ & 37 & 53.6 & 32 & 46.4 \\
\hline & Women: 223.8 & 194.8 & $>0.05$ & 1 & 20 & 4 & 80 \\
\hline Total & 214.4 & 208.1 & $>0.05$ & 38 & 51,4 & 36 & 48.6 \\
\hline
\end{tabular}

*Waist circumference risk values are different for men $(\geq 102 \mathrm{~cm}$ ) and women ( $\geq 88 \mathrm{~cm}$ ). The table expresses the means of the measured values before and after the intervention and the percentage of the reduction, considered as improvement, of these parameters: body mass index, waist circumference and blood total cholesterol level, in those subjects re-examined in 2012 or 2013 (depending on age medical checkup must be renewed every year for older than 50 years and every two years for younger seafarers), 74 of the subjects being overweight or obese in 2011 (69 men and 5 women). 
Table 3. Biomarkers' distribution among sexes

\begin{tabular}{|c|c|c|c|c|c|c|c|}
\hline \multirow[t]{2}{*}{ Biomarker } & \multicolumn{3}{|c|}{ Men } & \multicolumn{4}{|c|}{ Women } \\
\hline & $\mathbf{N}$ & Risk & $\%$ & $\mathbf{N}$ & Risk & $\%$ & $\mathbf{P}$ \\
\hline $\mathrm{HbA1c}$ & 159 & 58 & 36.5 & 13 & 3 & 23.1 & $>0.05$ \\
\hline hs-CRP & 154 & 17 & 11.25 & 13 & 2 & 15.38 & $>0.05$ \\
\hline TSH & 157 & 8 & 5.1 & 13 & 0 & 0 & $>0.05$ \\
\hline Microalbuminuria & 154 & 8 & 5.19 & 13 & 1 & 7.69 & $>0.05$ \\
\hline
\end{tabular}

HbA1c - glycated haemoglobin, hs-CRP - high-sensitivity C-reactive protein; TSH - thyrotropin; N - total number of individuals included; Risk - number of subjects with risk levels of biomarker; \% - percentage of subjects with biomarkers' risk levels; $p$ - statistical significance

Table 4. Biomarkers' risk values in both subgroups

\begin{tabular}{|c|c|c|c|c|c|c|c|}
\hline \multirow[t]{2}{*}{ Biomarker } & \multicolumn{3}{|c|}{ Patients $\geq \mathbf{5 0}$ years } & \multicolumn{4}{|c|}{ Patients 18-49 years (and risk factors) } \\
\hline & $\mathbf{N}$ & Risk & $\%$ & $\mathbf{N}$ & Risk & $\%$ & $\mathbf{P}$ \\
\hline $\mathrm{HbA1c}$ & 118 & 47 & 39.8 & 54 & 14 & 25.9 & $>0.05$ \\
\hline hs-CRP & 114 & 14 & 12.3 & 53 & 5 & 9.4 & $>0.05$ \\
\hline TSH & 117 & 7 & 6 & 53 & 1 & 1.9 & $>0.05$ \\
\hline Microalbuminuria & 114 & 8 & 7 & 53 & 1 & 1.9 & $>0.05$ \\
\hline
\end{tabular}

Abbreviations as in Table 3

[WHO] establishes that: Overweight is the value of BMI 25-29.9; obesity is $\mathrm{BMI} \geq 30$ ), yet not significantly ( $p>$ 0.05). Finally, in our selected population, most patients had normal values of waist circumference, but we found that high $\mathrm{HbA} 1 \mathrm{c}$ was more prevalent among those with risk values of waist perimeter ( $p<0.05$ ) (Fig. 1).

On the other hand, microalbuminuria was measured in 167 and was positive in 9 patients, showing a significant prevalence among individuals with high blood pressure $(p<0.05)$ compared with subjects with normal blood pressure.

No significant association was observed between TSH (measured in 170 individuals, risk value in 8) nor hs-CRP (measured in 167 subjects, high value in 19) and other parameter's risk values.

\section{DISCUSSION}

The prevalence of overweight and obesity in our population was lower than in the general Spanish population, according to the values given by the WHO (62\% overweight and $26.6 \%$ obesity) [18], and was also lower than other countries' seafarers (Hansen et al. [19] observed in 2010 that $70.5 \%$ of Danish seamen, all males, showed overweight or obesity, while Nas and Fışkın [20] found overweight or obesity in $52.1 \%$ of Turkish, males too, seafarers).

It is very interesting to notice the importance of the measurement of the abdominal perimeter in our protocol, since these workers often show a high BMI but not obesity, because of their great burliness. Undoubtedly, this parameter adds much quality to the checkups.
The reduction of the abdominal waist circumference and total cholesterol values in those individuals that we could follow up after they had received general medical advice on healthy habits was significant in men (we could only follow up 5 women, which is a very small sample). Possibly the medical advice given in 2011 exerted a positive effect.

However, the anamnesis referred to seamen diet in our electronic files program only admits "balanced" or "unbalanced", expressed by the patient. So, we think it could be recommendable to introduce a more detailed questionnaire on dietary habits in order to assess more precisely its correctness and to give adequate medical advice. Further research will be needed to determine its efficiency in the prevention and control of overweight, obesity and hypercholesterolaemia.

Related to biomarkers, the prevalence of $\mathrm{HbA} 1 \mathrm{c}$ risk values in our patients was similar to that observed in other populations, which is very alarming since diabetes mellitus is considered as a non fitness criterion for working on ships in Spanish Law. So, it is very important to detect these levels of $\mathrm{HbA} 1 \mathrm{c}$ as early as possible.

It is necessary to emphasize that glucose blood levels were within normal values $(<100 \mathrm{mg} / \mathrm{dL})$ in 37 of the 60 individuals with $\mathrm{HbA} 1 \mathrm{c}$ risk values included in this work, as occurred in other studies [7]. If we had not measured it, this risk situation would not have been detected.

It was also interesting that the association were found in our population between $\mathrm{HbA} 1 \mathrm{c}$ risk values and the presence of other cardiovascular risk factors: high glucose blood levels, 


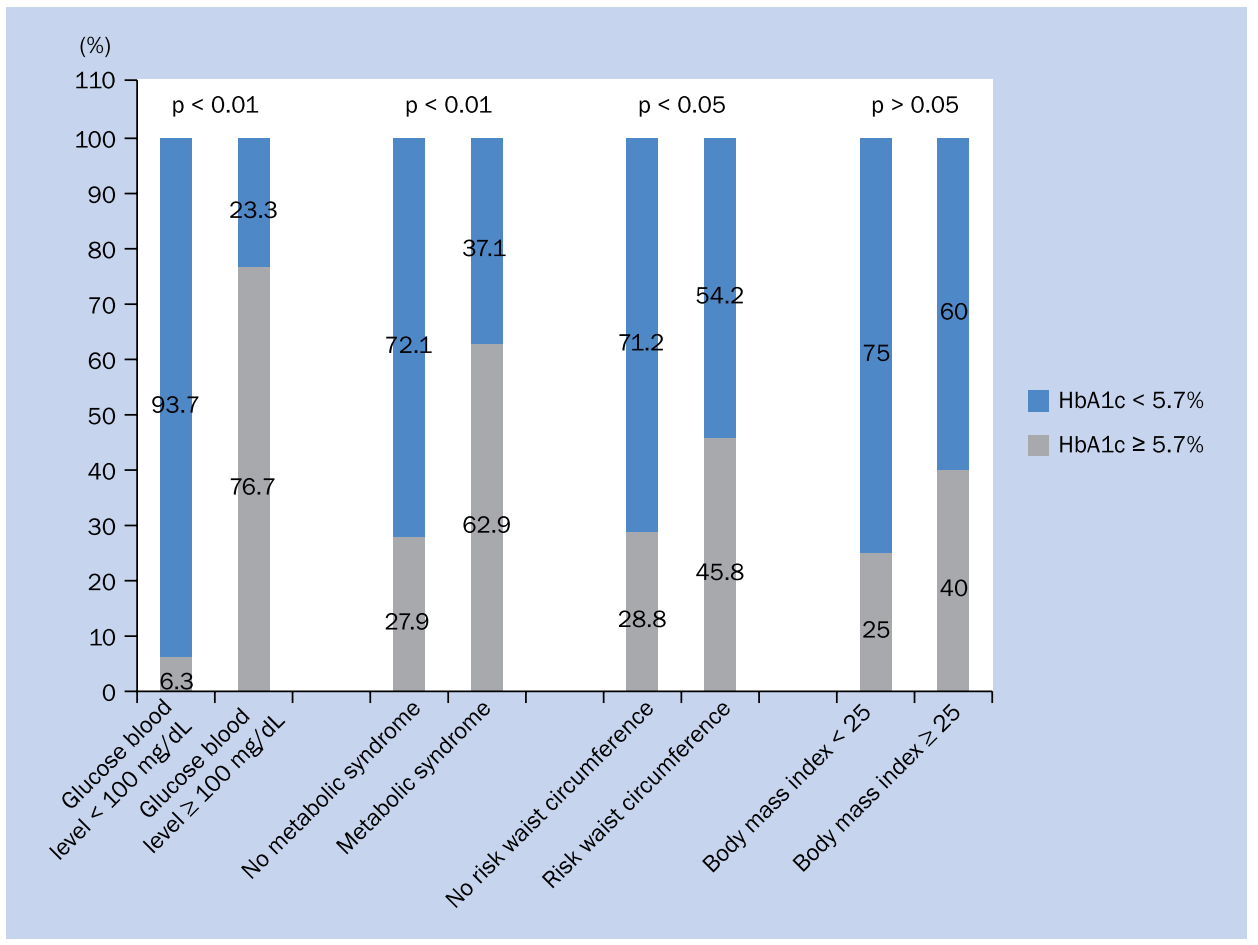

Figure 1. Association between glycated haemoglobin $(\mathrm{HbA1c})$ and other parameters. Measured in 172 individuals

overweight/obesity, high waist circumference and metabolic syndrome; as found in other scientific publications [21-24].

Considering HbA1c efficiency as a predictive cardiovascular disease marker, our findings and its good cost-effectiveness, it seems convenient to include its measurement in patients older than 50 and in younger patients with medium or high cardiovascular risk during pre-embarkation medical exams.

\section{ETHICAL CONSIDERATIONS}

We asked each individual for agreement to be part of this study, expressed by informed consent, according to the Spanish regulation currently in force.

The Instituto Social de la Marina also gave permission for the management of patients' data, under all guarantees established by valid Spanish laws.

\section{LIMITATIONS AND CHALLENGES OF THIS STUDY}

Since there is lack of research on seafarers' health, particularly in Spain, our study adds important information.

Our findings may lead to improve pre-embarkation medical checkups quality, as far as we introduce new biomarkers and questionnaires in our current protocols.

On the other hand, this study may have some bias due to the small size of the sample, the disproportion between sexes and the fact that all cases come from a unique Maritime Health Service.

Further investigation on seamen's health is needed using bigger samples and including subjects undergoing pre-embarkation medical examination in different Maritime Health Centres.

\section{CONCLUSIONS}

1. Since general medical advice on diet and physical activity showed a positive effect on the overweight and obese patients, the introduction of detailed questionnaires on dietary habits in our medical protocols for pre-embarkation checkups may result in a great benefit for seafarers' cardiovascular health.

2. The measurement of $\mathrm{HbA} 1 \mathrm{c}$ in the pre-embarkation medical exam in patients over 50 years or under that age with personal or familial cardiovascular risk background, may be useful in early diagnose of diabetes mellitus and as predictive marker of cardiovascular disease if $\geq 5.7 \%$.

3. The inclusion of both in our protocols will improve pre-embarkation medical exams quality and consequently, seafarers' health and wellbeing.

4. It should be also recommendable to obtain more implication of all concerned to get better labour conditions on board, particularly those related to balanced diet and physical activity during embarkation periods.

\section{REFERENCES}

1. Grau M, Elosua R, Cabrera de León A et al. Factores de riesgo cardiovascular en España en la primera década del siglo XXI: análisis agrupado con datos individuales de 11 estudios de base poblacional, estudio DARIOS. Rev Esp de Cardiología 2011; 64: 295-304. 
2. Carter T. Mapping the knowledge base for maritime health: 4 safety and performance at sea. Int Marit Health 2011; 62: 236-244.

3. European guidelines on cardiovascular disease prevention in clinical practice: executive summary. The Fifth Joint Task Force of the European Society of Cardiology and Other Societies on Cardiovascular Disease Prevention in Clinical Practice. Eur Heart J 2012; 33: 1635-1701.

4. Lubrano V, Balzan S. Consolidated and emerging inflammatory markers in coronary artery disease. World J Exp Med 2015; 5: 21-32.

5. van't Riet $\mathrm{E}$, et al. $\mathrm{HbA1C}$ is an independent predictor of non-fatal cardiovascular disease in a Caucasian population without diabetes: a 10-year follow-up of the Hoorn Study. Eur J Prev Cardiol 2012; 19: 23-31.

6. Silbernagel G, Grammer TB, Winkelmann BR, Boehm BO, März W. Glycated hemoglobin predicts all-cause, cardiovascular, and cancer mortality in people without a history of diabetes undergoing coronary angiography. Diabetes Care 2011; 34: 1355-1361.

7. Ashraf H, Boroumand MA, Amirzadegan A, Talesh SA, Davoodi G. Hemoglobin A1c in non-diabetic patients: an independent predictor of coronary artery disease and its severity. Diabetes Res Clin Pract 2013; 102: 225-232.

8. Koenig W. High-sensitivity C-reactive protein and atherosclerotic disease: from improved risk prediction to risk-guided therapy. Int J Cardiol 2013; 168: 5126-5134. doi: 10.1016/j.ijcard.2013.07.113.

9. Emerging Risk Factors Collaboration, Kaptoge $\mathrm{S}$ et al. C-reactive protein concentration and risk of coronary heart disease, stroke and mortality: an individual participant meta-analysis. Lancet 2010; 375: 132-140.

10. Choi J, Joseph L, Pilote L. Obesity and C-reactive protein in various populations: a systematic review and meta-analysis. Obes Rev 2013; 14: 232-244. doi: 10.1111/obr.12003.

11. Sarzosa Terán V, Astudillo Calle MA. Relationship of thyroid-stimulating hormone levels to development of dyslipidemia and determination of an ideal cut-off point to start replacement therapy. Endocrinol Nutr 2012; 59: 575-582.

12. Faber J, Selmer C. Cardiovascular disease and thyroid function. Front Horm Res 2014; 43: 45-56.
13. Posadas-Romero C, Jorge-Galarza E, Posadas-Sánchez R et al. Fatty liver largely explains associations of subclinical hypothyroidism with insulin resistance, metabolic syndrome, and subclinical coronary atherosclerosis. Eur J Endocrinol 2014; 171: 319-325.

14. Donnay S, Balsa JA, Álvarez J, Crespo C, Pérez-Alcántara F, Polanco C. Burden of illness attributable to subclinical hypothyroidism in the Spanish population. Rev Clin Esp (Barc) 2013; 213: 363-369.

15. Hara $\mathrm{H}$, Kougami $\mathrm{K}$, Shimokawa $\mathrm{N}$ et al. The prevalence and risk factors of microalbuminuria in hypertensive patients under current medical treatment. Intern Med 2014; 53: 1275-1281.

16. Xia F, Liu G, Shi Y, Zhang Y. Impact of microalbuminuria on incident coronary heart disease, cardiovascular and all-cause mortality: a meta-analysis of prospective studies. Int J Clin Exp Med 2015; 8: 1-9. eCollection 2015.

17. Gutiérrez-Repiso C, Rojo-Martínez G, Soriguer F et al. Factors affecting levels of urinary albumin excretion in the general population of Spain: the Di@bet.es study. Clin Sci (Lond) 2013; 124: 269-277.

18. http://www.who.int/mediacentre/factsheets/fs311/es/

19. Hansen HL, Hjarnoe L, Jepsen JR. Obesity continues to be a major health risk for Danish seafarers and fishermen. Int Marit Health 2011; 62: 98-103.

20. Nas S, Flşkın R. A research on obesity among Turkish seafarers. Int Marit Health 2014; 65: 187-191.

21. Al Rifai M, Silverman MG, Nasir K et al. The association of nonalcoholic fatty liver disease, obesity, and metabolic syndrome, with systemic inflammation and subclinical atherosclerosis: The Multi-Ethnic Study of Atherosclerosis (MESA). Atherosclerosis 2015; 239: 629-633.

22. Kodama S, Horikawa C, Fujihara K et al. Quantitative relationship between body weight gain in adulthood and incident type 2 diabetes: a meta-analysis. Obes Rev 2014; 15: 202-214.

23. Wang Y, Yu Q, Chen Y, Cao F. Pathophysiology and therapeutics of cardiovascular disease in metabolic syndrome. Curr Pharm Des 2013; 19: 4799-4805.

24. Reinoso Barbero L, Capapé Aguilar A, Díaz Garrido R, Santiago Dorrego C, Gómez Gallego F, Bandrés Moya F. Predicción del riesgo cardiovascular y su relación con el síndrome metabólico y los niveles de marcadores serológicos emergentes en vigilancia de la salud de los trabajadores. Arch Prev Riesgos Labor 2014; 17: 91-96. 